ESTUDIOS 



\title{
LA PERSISTENTE SOBERANÍA ${ }^{1}$
}

\author{
GIUSEPPE DE VERGOTTINI \\ Catedrático Emérito de Derecho Constitucional \\ Universidad de Bolonia
}

SUMARIO

I. Introducción.

II. La visión tradicional de la soberanía estatal.

III. El modelo Estado entre la crisis y la universalización.

IV. La necesaria confirmación de la función del Estado.

V. El mercado no anula la territorialidad.

VI. La globalización no destruye la soberanía.

VII. El mercado, los derechos, la democracia.

VIII. Soberanía europea: un problema inexistente.

IX. Renuncias a la soberanía y soberanía compartida: un problema inútil y falso.

X. A modo de conclusión.

\section{INTRODUCCIÓN}

El tema de la soberanía, aun siendo antiguo, sigue estando de actualidad. Cabe cuestionarse si continua siendo un concepto útil para definir la naturaleza del Estado, en la medida en que resulta evidente su inevitable integración en organizaciones intergubernamentales consideradas necesarias en el panorama internacional. Al mismo tiempo debe tenerse en cuenta la dificultad para utilizar este concepto, ya que dentro de los Estados suelen predominar entidades políticas

1 Traduccion de Y. Gómez Lugo (Prof. a de Derecho Constitucional de la Universidad Carlos III). 
territoriales menores. De este modo, tanto dentro como fuera de los ordenamientos estatales prosperan realidades más o menos institucionalizadas que persiguen intereses, en ocasiones, compatibles con los estatales, y en otras, en conflicto con éstos y que los Estados tienen dificultad para controlar.

Una reflexión detallada de esta temática puede abordarse ${ }^{2}$, también, con el fin de despejar dudas sobre la ambigüedad de la postsoberanía, que resultaría de la confusión de funciones entre las diferentes entidades políticas existentes en la actualidad $^{3}$.

Por tanto, lo que pretendemos es reflexionar sobre algunos de los problemas actuales que afectan al concepto moderno de soberanía. El hilo conductor de nuestra reflexión es la constatación de la permanencia de la institución «Estado» caracterizada por su soberanía, si bien no puede minimizarse totalmente el incremento de condicionantes, más o menos, preocupantes.

Desde hace tiempo se sostiene que el Estado actual es sólo la sombra lejana del Estado territorial inamovible (chiuso) del pasado. Su soberanía se ha visto afectada tanto por los procesos de descentralización del poder existentes en su interior, como por los procesos de integración pluriestatales a nivel internacional. La federalización de la ordenamientos estatales unitarios, la participación en procesos de integración entre Estados a nivel internacional y las indispensables relaciones de interdependencia entre Estados, y entre Estados y organizaciones o entidades de diversa naturaleza, constituyen elementos constantes en el panorama actual. La apertura a principios y normas establecidos por centros de decisión externos que afectan a áreas territoriales más amplias incide en la concepción tradicional de la forma Estado ${ }^{4}$. Centrándonos en el Estado constitucional de nuestros días, resulta conveniente determinar los factores críticos para la soberanía estatal presentes en el actual momento histórico y que afectan a sus rasgos internos y externos. Al mismo tiempo, debe reconocerse que estos factores probablemente no conduzcan a la superación del modelo Estado. La soberanía, tanto ayer como hoy, jamás se manifiesta de forma absoluta y debe reconocerse su carácter limitado, sin que ello implique negar su existencia ${ }^{5}$.

El Estado constitucional actual sigue siendo un «Estado» que pretende mantener los rasgos de la soberanía, si bien no pueden ignorarse esas tendencias. El problema que se plantea en la actualidad consiste en comprobar si la soberanía estatal sigue siendo una característica de las organizaciones políticas y si los pro-

2 Para una reflexión actual sobre el tema, véase AA.VV., «Sovranità vs. sovranazional», en Percorsi Costituzionali, 1. 2013.

3 Cfr. N. Mac Cormick, Sovereignity and After, en H. Kalmo y Q. Skinner, Sovereignity in Fragment. The Past, Present and Future of a Contested Concept, Cambridge, 2011, p. 151 y ss. Contra B. DE GiovanNI, "Il labirinto europeo», Lo Stato, 1/2013, 16.

4 Cfr. S. Bartole, «Stato (forme di)», en Enciclopedia del diritto, Annali, II, 2, Milano, 2008, p. 1132.

5 Sobre el tema, cfr. G. DE VERGOTTINI, «Garanzia della identità degli ordinamenti statali e limiti della globalizzazione», en C. Amato y G. Ponzanelli (dir.), Global Law v. Local Law. Problemi della globalizzazione giuridica, Torino, 2006, p. 9 y ss. 
cesos de cambio en curso, dentro y fuera del marco estatal, permiten mantener la confianza en las normas del Constitucionalismo que derivan de los principios «clásicos» de la democracia liberal basados en la garantía de los derechos individuales y colectivos y en el equilibrio entre poderes.

En concreto, el reto actual consiste en hacer compatible la superación del concepto de Estado territorial motivada por la denominada globalización con la garantía del mantenimiento del legado de derechos de libertad, civiles y políticos que constituyen la esencia del Estado constitucional.

Obviamente, y esta es una precisión que debe realizarse de forma clara para evitar malentendidos evidentes (clamorosi equivoci), debemos tener presente un condicionante importante: todo el debate sobre la función y los límites del Estado contemporáneo se restringe irremediablemente a una zona geopolítica que coincide con la euro-atlántica y sus posesiones en otros continentes. Grandes extensiones del mundo están claramente excluidas de este tipo de debate, ya que en estas últimas la organización del poder y el concepto de garantía es, por lo general, diferente (y en ocasiones, está a años luz). Allí donde el patrimonio cultural del constitucionalismo de origen euro-atlántico se desconoce o no se comparte está completamente fuera de lugar plantear el problema de una crisis de los conceptos de Estado y soberanía. Y no solo eso. Además, puede añadirse que el efecto jurídico-cultural del constitucionalismo euro-atlántico y la crisis relacionada con la soberanía-Estado parecen menos frecuente en algunas áreas geográficas. En concreto, no parece que pueda aplicarse en contextos en los que no se utiliza la categoría de Estado-nación, ni el elemento esencial de la territorialidad del derecho. Esto sucede, en particular, cuando se aplican los principios del derecho islámico, que se implementan no respecto a un Estado concreto, y por tanto, un territorio determinando, sino a una comunidad de fe y derecho ${ }^{6}$.

\section{LA VISIÓN TRADICIONAL DE LA SOBERANÍA ESTATAL}

El Estado es considerado habitualmente una institución «soberana», ya que conforme a la doctrina tradicional de derecho público el poder político que lo caracteriza es supremo, originario y absoluto respecto a otros poderes superiores ${ }^{7}$.

6 Cfr. C. SBAIlò, Principi sciaritici e organizzazione dello spazio pubblico nel mondo islamico. Il caso egiziano, Padova, 2012, p. 91 y ss.

7 Sobre el perfil histórico de la soberanía, para un concepto actual de la misma véase L. FerrajoLI, La souranità nel mondo moderno. Nascita e crisi dello stato nazionale, Milano, 1995; G. SiLveSTRI, «La parabola della sovranità. Ascesa, declino e trasfigurazione di un concetto", en Rivista di diritto costituzionale, 1, 1996, p. 26 y ss.; P. PAssaglia, «Sovranità», en S. CASSESE (dir.), Dizionario di diritto pubblico, IV, Milano, 2006, p. 5643 y ss.; G. Berti, «Sovranità», en Enciclopedia del diritto, Annali, 1, Milano, 2007, p. 1067 y ss.; N. MACCORMICK, Questioning Sovereignty. Law, State and Nation in the European Commonwealth, Oxford, 2008; D. GRIMM, Souveränetät, Berlin, 2009; IDEM, «Souveraineté», en M. Troper y D. Chagnollaud (dir.), Traité. International de droit constitutionnel, I, Paris, 2011, p. 547 y ss. 
En la acepción predominante, el concepto de soberanía se relaciona con el carácter originario (originarietà), en cuanto que el Estado es considerado un ente capaz de legitimarse a sí mismo y, por tanto, no procede de otra institución. Obviamente, el carácter no derivado, y por tanto la originarietà, deben entenderse en sentido jurídico, y no histórico, dado que históricamente son numerosos los ejemplos de Estados que proceden de un acto de voluntad de otros Estados (concesión unilateral de independencia o resolución derivada de un tratado internacional). La originarietà aparece relacionada con la independencia, que implica la capacidad de evitar influencias por parte de otros Estados una vez que el Estado soberano se constituye como tal. Desde esta perspectiva, la soberanía y la independencia, proyectadas en las relaciones internacionales, son consideradas sinónimos. Por último, la soberanía comporta la capacidad jurídica del Estado para establecer el ámbito de su competencia de intervención (la denominada «competencia de la competencia»), así como para adoptar cuantas medidas sean necesarias para su protección (la denominada auto-garantía).

En otro sentido, se habla de la soberanía del Estado en referencia a las relaciones existentes con ordenamientos jurídicos (ordinamenti) y sujetos (soggetti) incluidos en el ordenamiento estatal para enfatizar la supremacía del poder del Estado (Estado-Gobierno) sobre los diferentes sujetos creados dentro del mismo. En este supuesto, se observa que la soberanía dentro del ordenamiento se articula en una serie de «potestades soberanas» que tienen por objeto las homónimas actividades de los órganos que ejercen el poder legislativo, ejecutivo y judicial según la tradicional división tripartita; que, sin embargo, para una consideración más precisa, habría que añadir la constituyente, la de indirizzo político y la de revisión constitucional. Las potestades que integran la soberanía pueden estar centralizadas en un único sujeto o repartirse entre sujetos diferentes, con una evidente riqueza de combinaciones posibles procedente de la compleja variedad de formas de gobierno incluidas en las formas históricas de Estado ${ }^{8}$.

\section{EL MODELO ESTADO ENTRE LA CRISIS Y LA UNIVERSALIZACIÓN}

La soberanía del Estado contemporáneo padece serias dificultades e incluso fragmentación y desgaste, tanto por la integración en la comunidad internacional y en sus organizaciones ${ }^{9}$, como por el surgimiento de autonomías políticas inter-

8 Para un resumen sobre estas reflexiones, ampliamente compartidas por la doctrina constitucionalista, véase, G. DE Vergottini, Diritto costituzionale comparato, 9 ed., Padova, 2013, p. 134 y ss.

9 Para el proceso de erosión de la soberanía a consecuencia de la incorporación del Estado en la Unión Europea, véase R. BARATTA, «Logoramento e frammentazione della sovranità nazionale nel processo di integrazione europea», en Archivio giuridico, 4/2012, p. 489 y ss. 
nas. En particular, se ha aludido al fenómeno de la globalización para subrayar la crisis del Estado.

Los cambios históricos que han afectado a la política y la economía han puesto en tela de juicio el modelo de Estado y los poderes estatales tradicionales: el proceso de desmaterialización de la riqueza ha dado lugar a la separación progresiva entre el Estado y el mercado; las organizaciones supranacionales tienden a limitar considerablemente las funciones soberanas, tanto desde el punto de vista interno como externo al territorio del Estado; diversos organismos internacionales con funciones jurisdiccionales (recientemente, la Corte Penal Internacional para los crímenes contra la humanidad, cuyo Estatuto fue firmado por 139 países en 1998, ratificado por 114 y está en vigor desde 2002) han reconocido la capacidad para hacer cumplir sus decisiones por los Estados en casos concretos; las alianzas militares afectan a la disponibilidad de las Fuerzas Armadas de los países e imponen formas de limitación de la soberanía; las empresas multinacionales actúan en el mercado mundial al margen de los controles estatales tradicionales. En relación con estos fenómenos se ha hablado de crisis del Estado, en la medida en que se produciría un eclipse o erosión de la soberanía; igualmente, se ha señalado que el Estado ha dejado de ser el único sujeto exclusivo de la política, el único centro autónomo de poder ${ }^{10}$. El Tribunal Constitucional italiano ha reconocido «la progresiva erosión de la soberanía nacional en el plano internacional, especialmente como consecuencia del avance progresivo de la integración europea» (365/2007). Desde este punto de vista, la erosión coincide con los límites que el artículo 11 de la Constitución admite en situaciones concretas y que son imprescindibles para permitir la satisfacción de los intereses propios del Estado. Si esto es cierto, resulta difícil comprender a título de qué se debe equiparar el fenómeno de las limitaciones de la soberanía con la convicción de la superación del Estado. En efecto, hay que señalar que esta observación acerca de la crisis del Estado trata, en realidad, sobre el debilitamiento del poder del Estado (esto es, de su soberanía) más que sobre el concepto mismo de Estado; institución, que se mantiene y es imposible reemplazar de raíz con otras soluciones organizativas.

En nuestra opinión, basada en elementos probatorios, el Estado no ha desaparecido de la escena. El Estado existe, pese a su siempre recordada crisis; y existe la forma de poder que se define como soberanía, a pesar de sus cesiones y limitaciones jurídicas o de facto ${ }^{11}$. A este respecto, con el objeto de descartar algunos argumen-

10 Sobre la crisis del Estado, para un resumen de las causas en general que sostienen esta opinión, véase F. Riccobono, «Crisi dello stato e legittimazione democratica», en S. LABriola (dir.), Ripensare lo stato, Milano, 2003, p. 51 y ss. Cfr. también, C. Schreuer, «The Waining of the Sovereign State: towards a New Paradigm for International Law», en European Journal of International Law, 1993, p. 447 y ss.; A. BALDASSARre, Globalizzazione contro democrazia, Roma-Bari, 2002; S. CASSESE, Oltre lo stato, Roma-Bari, 2006; E.W. BöcKenförde, Stato, costituzione, democrazia. Studi di teoria della costituzione e di diritto costituzionale, Milano, 2006.

11 Sobre la permanencia del concepto, cfr. H. Kalmo y Q. Skinner, Sovereignity in Fragment. cit., passim. 
tos recurrentes e imprecisos, conviene aclarar que debe distinguirse entre los conceptos de limitaciones de soberanía y cesiones de soberanía. No se trata de una diferencia trivial y el Conseil Constitutionnel lo señaló claramente en una sentencia de 1976: las limitaciones a la condición de reciprocidad son admisibles constitucionalmente. No así, las «transferencias» de soberanía a organizaciones internacionales que estarían prohibidas en cualquier caso $^{12}$. En la célebre sentencia sobre el Tratado de Lisboa ${ }^{13}$ el Bundesverfassungsgericht excluyó las cesiones/transferencias de soberanía. Las competencias asignadas a la Unión son atribuciones limitadas, la soberanía permanece en los Estados y el efecto directo de los actos adoptados por la Unión Europea es consecuencia de la voluntad estatal. En el fondo existe una interpretación estricta del principio democrático protegido por el art. 79.3. ${ }^{\circ}$ de la Ley fundamental que, según el Tribunal, está garantizado al máximo por los órganos estatales y no está encomendado a la Unión ${ }^{14}$. Una limitación está totalmente justificada si procede de la libre determinación voluntaria sin afectar a la esencia de la soberanía. La cesión también está justificada cuando se refiere no a la soberanía, porque en ese caso se correría el riesgo de afectar a la esencia de un sujeto soberano, sino a aspectos concretos de las competencias del Estado. En caso extremo, una «cesión» en sentido estricto significaría renuncia y, por tanto, superación del poder soberano a favor de otro sujeto que oscurece la fuerza de atracción (forza di assorbimento) como en el caso de transformación de una confederación en un Estado federal. Es este último el caso, hoy completamente imposible, de la transformación actual de la Unión Europea en algo que recuerda a un Estado Federal. En este sentido, debe precisarse que en el actual momento histórico los Estados, aunque fuertemente limitados en sus tradicionales poderes soberanos, algunos más que otros, no han abandonado la idea de ser, y sentirse, soberanos, miembros libres de la Unión y de otros organismos internacionales. El artículo 88.1. ${ }^{\circ}$ de la Constitución francesa modificada establece que la participación en la Unión deriva de la libre voluntad de los Estados de ejercer en común algunas competencias en virtud del Tratado de Lisboa de 13 de diciembre de 2007. Por tanto, se trata de una decisión soberana que supervisa las limitaciones del poder estatal y la transferencia de atribuciones a la Unión. Muy convincente resulta el ejemplo de voluntad expresada por el Reino Unido en la European Union Act de 2011, en la que reivindica la soberanía nacional como el fundamento último del principio que permite la auto-restricción del ordenamiento interno a favor de la primacía del derecho de la Unión (section 18: sovereignty clause) $)^{15}$.

Desde hace tiempo se habla también de crisis del Estado, confundiéndose situaciones de mera dificultad para desarrollar formas de organización adecuadas

12 Dic. n. ${ }^{\circ} 76-61$ de 30 diciembre de 1976.

13 BVerfGE 123267 (2009).

14 Sobre ello, puede consultarse un análisis más detenido en D. GRIMM, Souveraineté, cit., p. 598 y ss.

15 M. Gordon y M. Douglas, "The United Kingdom's European Union Act 2011: "Who Won the Bloody War Anyway?”, en European Law Review, 2012, p. 6 y ss. 
para satisfacer los intereses generales y de ineficacia de la organización pública con situaciones en las que el poder estatal está limitado jurídicamente por la incorporación del Estado en el marco de la comunidad internacional.

En otras palabras, la dimensión internacional del concepto «crisis» se refiere a situaciones de verdadera desaparición de la soberanía: casos de disolución del Estado, como a raíz de la crisis yugoslava; casos de devolución de competencias propias de la soberanía a organismos internacionales, como en el caso de la construcción paulatina de la Unión Europea; supuestos de condicionantes indirectos y de incorporación de restricciones jurídicas directas, como el establecimiento de limitaciones a la soberanía tradicional del Estado, entre las que se incluyen los derechos humanos consolidados como núcleo de los principios del derecho internacional que son vinculantes para los Estados.

Por lo que se refiere a la dimensión nacional de la configuración del poder, en ocasiones, la crisis del Estado es considerada como la incapacidad para satisfacer las exigencias de los ciudadanos (crisis del Estado social, crisis de gobernabilidad), la incapacidad para afrontar sus expectativas genera desconfianza (crisis de legitimidad), la limitación de los ámbitos de intervención del Estado debido a la asunción de competencias por parte de entes astatali como la Unión Europea (sustracción de competencias), el sometimiento a un sistema de derechos como límite absoluto al poder del Estado (soberanía de los derechos que desdibuja la del ente estatal). Así, actualmente la crisis del Estado se asocia ineludiblemente a la grave crisis económica general que muestra la incapacidad e imposibilidad de los Estados para sostenerse, lo que pone de manifiesto la necesidad de ayuda y coordinación entre los diferentes niveles de los poderes públicos (Unión Europea-Estado-Regiones) y muestra como la solución puede encontrarse en decisiones adoptadas por organizaciones como la Unión Europea y a través de nuevos acuerdos destinados a remediar situaciones difíciles planteadas en el seno de las economías de los Estados. La crisis económica se transforma en crisis social que, a su vez, cuestiona la capacidad del Estado y sus instituciones. Sobre ello, debe puntualizarse que la mencionada crisis del Estado no implica necesariamente crisis del modelo organizativo estatal, sino más bien crisis referida a situaciones concretas en las que un Estado se encuentra ante dificultades o incluso fracasa.

Existen motivos fundados para considerar factible el mantenimiento de la actual forma Estado en el escenario mundial. Y ello, debido a la ausencia de una forma política viable diferente del Estado y a la falta de legitimidad democrática de las organizaciones internacionales y supranacionales (que no permiten nuevas atribuciones de competencias o funciones soberanas en detrimento del Estado nación) en un contexto de escasa efectividad del derecho internacional ${ }^{16}$. Además, debe señalarse que, en general, en la actualidad no existen, ni se conocen, organi-

16 E. DE MARCO, «La sovranità dello stato fra "pluralismo" e “integrazione sovranazionale” ", en 1989, 1994, p. 223 y ss. 
zaciones internacionales que puedan gozar de soberanía ${ }^{17}$. Asimismo, las reflexiones sobre la crisis del Estado no parecen contradecir la forma de Estado como modelo. Así, puede hablarse de crisis de un determinado Estado cuando se constata que el mismo ha perdido los requisitos de plenitud de poder y absoluta autosuficiencia; requisitos que, por otro lado, no siempre han estado presentes en el Estado territorial inamovible del pasado, sin que ello signifique la superación de la forma de Estado como modelo organizativo válido.

A este respecto, debe señalarse que en la experiencia reciente y actual se sigue asistiendo a una universalización del modelo ${ }^{18}$ de Estado territorial de origen europeo y a la continua expansión del modelo cuando nuevas realidades político territoriales se constituyen en entes independientes. No hay comunidad nacional que acceda a la independencia y no pretenda hacer uso de instituciones típicas de la tradicional forma de Estado desarrollada por la experiencia de los Estados europeos del pasado revistiendo la forma de Constitución. A modo de ejemplo, puede mencionarse el caso de Kosovo que con la ayuda de la comunidad internacional, pero con rígidas reservas por parte de algunos países que no tienen la intención de reconocer su soberanía, ha pasado de ser una provincia serbia a ser un Estado territorial ${ }^{19}$. Otro ejemplo lo constituye la pretensión de lograr un Estado palestino a través del pleno reconocimiento de su soberanía; pretensión, que se mantiene debido a la oposición del Estado israeli ${ }^{20}$. Estado y Constitución, derivados de la evolución del Constitucionalismo europeo, o si se prefiere occidental, con los ajustes necesarios exigidos por las peculiaridades locales, han servido de modelo para la generalidad de los nuevos Estados independientes. Los procesos de state-building o nation-building en el marco de Naciones Unidas no son más que esfuerzos - a menudo totalmente irreales — para implantar en sociedades desorganizadas instituciones del Estado constitucional de origen liberal occidental ${ }^{21}$. Estos nuevos entes recurren sin reparos al concepto de soberanía, tanto a nivel interno como externo, afirman la unidad e intangibilidad del territorio y consideran ineludible los tres elementos: territorio, pueblo y poder del Estado. Su condición de Estado se consolida firmemente, mientras que la democracia y los derechos humanos pueden considerarse no indispensables para la declaración de soberanía. Por tanto, incluso en la actualidad, cuando se piensa en la creación de nuevos entes políticos parece imposible renunciar a la idea de un espacio territorial cerrado a la injerencia de los demás, como exige la Carta de Naciones Unidas, y a utilizar los conceptos tradicionales de Estado y soberanía ${ }^{22}$.

17 Cfr D. Grimm, Souveraineté, cit., p. 594.

18 Cfr. M. Van Creveld, The Rise and Decline of the State, Cambridge, 1999, p. 263 y ss.

19 Cfr. M. Mazza, L'ordinamento costituzionale del Kosovo, Napoli, 2008.

20 Cfr. J. Quigley, The Statehood of Palestine, Oxford, 2010.

21 Cfr. W. Reinhard, Storia del potere politico in Europa (trad. it.), Bologna, 2001, p. 581 y ss.

22 Cfr. amplius G. De Vergottini y T. E. Frosini (dir.), «Libertà e sicurezza», en Percorsi costituzionali, 1/2008; I. PAPANICOLOPUlu y T. SCOVAZZI (dir.), Conflitti armati e situazioni di emergenza : la risposta del 
De este modo, se constata como en las experiencias más recientes habidas a nivel global se ha asistido a una generalizada expansión del modelo de Estado territorial de origen europeo, y por tanto, a una mayor difusión del mismo. En consecuencia, debe admitirse que la forma tradicional de poder político denominada «Estado» ha resultado útil como vehículo de formación de la identidad nacional de nuevos territorios. Entre otras cosas, resulta evidente que la guerra mantenida durante las décadas pasadas por diversos pueblos para lograr su independencia respecto de las potencias coloniales ha sido la «via regia» para la formación del Estado y, aun cuando incierta o inexistente, de la Nación. No ha habido ninguna comunidad nacional que, en la segunda mitad del siglo pasado y principios del actual, haya logrado la independencia y no pretendiera utilizar las instituciones tradicionalmente típicas de la forma estatal desarrollada históricamente en la evolución de los Estados europeos. En el intento, no siempre logrado como demuestra la experiencia de muchos Estados fallidos (failed states), por consolidar nuevos poderes territoriales no puede faltar una referencia a la experiencia de realidades institucionales consolidadas. El tradicional instrumento constitucional estaba disponible y ha sido utilizado adecuadamente. «Estado» y «Constitución», procedentes del Constitucionalismo europeo o si se prefiere occidental, con los ajustes y modificaciones necesarias para permitir la eventual actuación de ideologías y programas políticos en las diferentes fases constitucionales, se han convertido en el modelo a seguir para los Estados que han accedido a la independencia recientemente.

Realizadas estas precisiones, la crisis debe referirse más bien a Estados desarrollados que atraviesan una especie de retroceso en su desarrollo o a Estados donde los mecanismos institucionales previstos formalmente han resultado inadecuados. Por el contrario, carecería de sentido hablar de crisis del Estado en aquellos supuestos en que el Estado no ha sido capaz de consolidarse de acuerdo con el modelo europeo de Estado constitucional como referencia, debido a la ausencia de una sociedad civil basada en valores e infraestructuras socioculturales similares a las occidentales; en dichas circunstancias, el Estado no existe o es una mera ilusión. En ese caso, el modelo se habría reflejado solo parcialmente, ya que faltarían los requisitos de estilo occidental que permiten que funcione.

El fenómeno de los Estados «ficticios» o «fallidos» (failed states) ${ }^{23}$, al que los politólogos han dedicado especial atención, tiene importancia cuantitativa, pero

diritto internazionale: relazioni al ciclo di conferenze tenuto nell' Universita di Milano-Bicocca (marzo-aprile 2006), Milano, 2007; SCHILlaci A., Diritti fondamentali e parametro di giudizio per una storia concettuale delle relazioni tra ordinamenti, Napoli, 2012; M. AnNATI y T. ScovazZI (dir.), Diritto internazionale e bombardamenti aerei, Milano, 2012; A. Lanciotti y A. TANZI (dir.), Uso della forza e legittima difesa nel diritto internazionale contemporaneo, Napoli, 2012.

23 Cfr. R.H. Jackson, Quasi-States. Sovereignty, International Relations, and the Third World, Cambridge, 1990. Sobre los Estados con soberanía limitada, véase R. OrRù y L.G. Sciannella (dir.), Limitazioni di sovranità e processi di democratizzazione, Torino, 2004; M. RAvEraIra, «La sovranità degli stati nel puzzle europeo tra sovranazionalità e intergovernatività», en Percorsi Costituzionali, 1/2013, p. 33 y ss. 
escasa importancia para demostrar la supuesta crisis del «modelo Estado» en el ámbito de los Estados constitucionales que caracterizan actualmente la forma de Estado de origen liberal.

En realidad, la condición de Estado y la soberanía existen en los ordenamientos que demuestran capacidad para hacer cumplir o, al menos, garantizar la relevancia de sus decisiones en el ámbito de la comunidad internacional. Y esto se aplica a los Estados que son capaces de promover la protección preferente de sus intereses nacionales, incluso, recurriendo a la fuerza y que, en cualquier caso, manifiestan una verdadera vocación hegemónica imponiendo su voluntad en el escenario internacional. También se aplica para la generalidad de Estados cuando está en peligro su supervivencia por la amenaza terrorista. En estos casos, solo una referencia sin reservas a las posibilidades de reacción que ofrece la soberanía ha permitido poner en marcha instrumentos considerados inevitables para garantizar la protección de sus comunidades amenazadas de agresión.

\section{LA NECESARIA CONFIRMACIÓN DE LA FUNCIÓN DEL ESTADO}

El Estado, por tanto, tiene todavía razón de ser. En las democracias actuales debe reconsiderarse su papel y compatibilizarlo con la necesidad reconocida de acudir a soluciones organizativas pluriestatales a las que se confían funciones que el Estado no puede asumir por sí solo. Desde esta perspectiva, la intervención de organismos como la Unión Europea resultan útiles para satisfacer los intereses que el Estado no puede garantizar por sí mismo; un ejemplo de ello lo constituye las intervenciones comunitarias en materia de competencia (antitrust) que son capaces de controlar y mitigar los abusos de posición dominante y las grandes fusiones anticompetitivas que el Estado no podría controlar. A pesar de las ineludibles limitaciones de soberanía libremente consentidas a través de acuerdos especiales interestatales, el Estado debe seguir existiendo, ya que todavía tiene una función importante que desempeñar en el escenario mundial donde los intereses de los más débiles sólo se escuchan cuando están presentes Estados que asuman esta labor ${ }^{24}$. Pero existen, y continuarán existiendo, sectores de actividad de los que sólo puede ocuparse fundamentalmente el Estado que, entre otras cosas, también puede ser destinatario de nuevas tareas: la regulación de la ciudadanía, la garantía de la seguridad de los ciudadanos, el sistema de protección jurisdiccional de derechos, la cultura, la educación, la gestión territorial. Pero esta reflexión corre el riesgo de limitarse al Estado constitucional que habitualmente nos ocupa

24 T. Vassalli Di Dachenhausen (dir.), Atti del Convegno in memoria di Luigi Sico : il contributo di Luigi Sico agli studi di diritto internazionale e di diritto dell'Unione europea: Università degli studi di Napoli Federico 2., 23 aprile 2010, Napoli, 2011; C. Nine, Global Justice and Territory, Oxford, 2012. 
cuando traemos a colación el tema de la crisis. La situación es completamente diferente si nos abstraemos de la dimensión euro-atlántica y nos centramos en una perspectiva realmente global. En este supuesto todo cambia, ya que es realmente incomprensible no querer darse cuenta de que aún permanecen intactos los viejos tabúes de la condición de Estado ligada al férreo control del territorio. Efectivamente, se confirma que el territorio sigue teniendo un valor añadido, incluso en las Constituciones más recientes inspiradas en los valores propios del Estado constitucional contemporáneo mencionados anteriormente; y ha sido, y sigue siendo, objeto de cláusulas de tratados internacionales que establecen pactos de seguridad colectiva dirigidos a mitigar los peligros de agresión por parte de terceros Estados. En concreto, tras la Segunda Guerra Mundial, no sólo se consolidó el principio de soberanía territorial, como establece la misma Carta de Naciones Unidas (artículo 2, apartados 2..$^{\circ}$ y $7 .^{\circ}$ ), sino que determinados instrumentos internacionales establecieron de forma oportuna el principio de inviolabilidad de las fronteras (Acta Final de Helsinki). A este respecto, quedan confirmados los tradicionales principios de Westfalia ${ }^{25}$.

Asimismo, resulta interesante señalar cómo los numerosos casos en que el derecho internacional y el derecho nacional prevén supuestos que permiten superar el principio de territorialidad deben considerarse como excepciones al mismo, que continua siendo parámetro de referencia. Por tanto, la territorialidad está, en principio, fuera del ámbito de la jurisdicción estatal. Aunque en 1927 el Tribunal permanente de la Haya reconoció la jurisdicción del Estado agredido fuera de sus fronteras (caso Lotus). En la actualidad asistimos a un indirizzo amplio de los efectos extraterritoriales de las medidas estatales encaminadas a la protección de valores con alcance universal como los derechos humanos, el medio ambiente o el control de armas de destrucción masiva. En concreto, cabe señalar lo que está sucediendo con los principios desarrollados en materia de persecución de graves violaciones del derecho humanitario; la consagración del derecho de los Estados a perseguir y enjuiciar al infractor, incluso si el delito se ha cometido fuera su ámbito territorial (caso Eichmann, 1961), se considera una excepción al principio de territorialidad. En este sentido se ha pronunciado el Tribunal de Estrasburgo en el caso Bankovic (2001). La observancia del principio de territorialidad vinculado por el juez a la soberanía ha sido reiterado por el Tribunal de Luxemburgo en relación con las medidas de tráfico aéreo en el caso The Air Transport Association of America (caso C-366/10, de 21 diciembre 2011).

De este modo, nos guste o no, el principio de territorialidad sigue caracterizando la forma Estado, ya sea por Estados que ejercen un papel de liderazgo en la comunidad internacional o por Estados con un perfil completamente secundario. En efecto, el territorio sigue considerándose esencial e indispensable para la posi-

25 Consúltese, L. S. Rossi y G. Di Federico (dir.), L'incidenza del diritto dell'unione europea sullo studio delle discipline giuridiche, Napoli, 2008. 
ble existencia de toda comunidad política organizada que aspire a la autosuficiencia a través de su independencia. Esto resulta de aplicación a la formación de nuevos Estados. El conflicto entre Palestina e Israel es un caso emblemático porque también es esencial el reconocimiento del poder palestino sobre las pequeñas extensiones de tierra. En todos los ejemplos de separación planteados tras la disolución de la URSS y la ex Yugoslavia, los graves conflictos que han surgido han sido justificados por las realidades estatales en vía de creación para ejercer un control total sobre sus territorios. Además, incluso tras un periodo no precisamente breve en que se sigue hablando de decadencia de la forma Estado, continúan consolidándose en todo el mundo nuevos Estados territoriales que se incluyen en el marco de Naciones Unidas.

El territorio es también importante para la ampliación de ámbitos territoriales de poder de Estados existentes, y la adquisición de nuevos territorios sigue siendo fuente de tensiones y posibles conflictos. Un ejemplo actual es la reclamación china para considerar como territorios propios amplias áreas fuera de sus fronteras actuales; en los nuevos pasaportes chinos se imprime un mapa de China que incluye en India el territorio de Arunachal Pradesh que pasó a llamarse Tíbet del sur, las islas del mar del Sur de China, desde el archipiélago Paracel al Spraty, territorios reivindicados por Vietnam, Filipinas, Malasia y Brunei, así como Taiwán.

En los ordenamientos jurídicos de las democracias occidentales, pese a la proliferación de formas de integración con reconocimiento de mayores facultades a las denominadas organizaciones supranacionales (como la Unión Europea), los Estados miembros basados en su tradicional territorialidad conservan, y no renuncian, a cierto control sobre el territorio como demuestra el mantenimiento de un rol decisivo del modelo de acuerdo intergubernamental en la adopción de decisiones en materia de seguridad ${ }^{26}$.

En resumen, el territorio sigue desempeñando un papel esencial en la determinación de la forma Estado que, en su conjunto, se mantiene como modelo de referencia de la organización del poder político. Asimismo, se confirma el vínculo inseparable entre Estado, soberanía y control del territorio como, por ejemplo, demuestran los movimientos independentistas que incitan a la secesión. A modo de ejemplo, puede mencionarse el contenido de la proclamación de la soberanía del Parlamento de Cataluña de 24 de enero de 2013 que, a pesar de la intervención del Tribunal Constitucional español, fue seguida de un referéndum popular en noviembre de 2014. Otro ejemplo se encuentra en el referéndum sobre la independencia de Escocia celebrado en septiembre de 2014.

En última instancia, el territorio continúa siendo el ámbito espacial coesencial para la existencia del Estado y de su soberanía, y constituye el ámbito de

26 G. L. Falchi, A. IACCARINO, Legittimazione e limiti degli ordinamenti giuridici - Colloquio giuridico internazionale, Roma, 2012. 
ejercicio del poder soberano, esto es, de los poderes del Estado. La aplicación del derecho nacional está, por tanto, vinculada de forma natural al territorio, pero en determinados supuestos puede tener también alcance extraterritorial. Sobre este punto, y por razones de sistemática, no nos demoraremos más en esta cuestión. Sin embargo, parece oportuno recordar que esta observación ha sido corroborada no sólo por la doctrina, sino también por numerosos argumentos judiciales (véase, por ejemplo, las Conclusiones del Abogado General Darmon de 25 de mayo de 1988, en los casos acumulados 89/85, 104/85, 114/85, 116/85, 117/85, 125 $129 / 85)^{27}$. Del mismo modo, casos como el reciente y conocido asunto Marò, sobre la valoración judicial de la actuación de los oficiales de la marina italiana en el ejercicio de tareas de seguridad en el ámbito de una misión internacional contra la piratería atestiguan el carácter ordinario del ejercicio territorial de los poderes soberanos, así como sus puntos problemáticos. De hecho, su actuación tuvo lugar a bordo del buque mercantil Enrica Lexie, pero de arreglo a los preceptos de las resoluciones adoptadas por el Consejo de Seguridad de Naciones Unidas sobre la cuestión, esto es, las recomendaciones de la Organización Marítima Internacional (OMI) y la ley italiana.

\section{EL MERCADO NO ANULA LA TERRITORIALIDAD}

El fenómeno de las relaciones transnacionales entre agentes económicos, cuyos intereses trascienden las fronteras del Estado, no significa que las exigencias del mercado puedan satisfacerse prescindiendo completamente de la mediación del poder público situado en el territorio de un Estado concreto. Y en consecuencia, las exigencias del mercado no implican la desaparición del importante control del Estado sobre el territorio. Probablemente la mayoría de los observadores de las relaciones internacionales, que ven un rol cada vez más relevante de las empresas en competencia y también sustitutivo de la función de los poderes públicos, ha llegado a conclusiones apresuradas acerca de la superación del rol de los Estados nación. Estos últimos mantienen un papel indiscutible en su interior para el gobierno de su territorio y su ciudadanía, así como para proteger a sus ciudadanos, la educación y la cultura. En las relaciones internacionales sigue desempeñando su papel de garantía de la seguridad, aunque de diferente envergadura en virtud del peso político y estratégico de cada Estado.

El tradicional nomos de la soberanía territorial convive con el del mercado. Así, el primero no desaparece por el mero hecho de que el Estado deba tolerar o aceptar el papel de las empresas que persiguen sus propios intereses, aún sin interferencia de los poderes públicos del Estado o, incluso, imponiendo sus propias normas con-

27 Para una lectura de las mencionadas Conclusiones puede consultarse la web: http://eur-lex.europa.eul LexUriServ/LexUriServ.do? uri=CELEX:61985CC0089:IT:HTML 
trarias a las estatales. Del mismo modo, el nomos de la soberanía territorial no está superado si el Estado acepta mediante un acuerdo internacional formas de colaboración que implican el funcionamiento en su territorio de normas que se consideran útiles para la satisfacción de los intereses comunes, entre los que se incluye la lucha contra la delincuencia, la protección de los derechos humanos y, en especial, la protección de la seguridad y la resolución de los conflictos internacionales.

\section{LA GLOBALIZACIÓN NO DESTRUYE LA SOBERANÍA}

Suele afirmarse que la crisis del Estado se habría agravado debido a la denominada globalización que, con frecuencia, se invoca al hilo de la crisis, o incluso de la superación de la institución «Estado». Pero como todas las síntesis de definiciones, también la de la globalización implica graves aproximaciones y errores inaceptables.

La globalización implica la superación de los términos tradicionales de referencia de la soberanía y, en particular, el abandono del territorio estatal como espacio del derecho y de la soberanía ${ }^{28}$.

En primer lugar, habría una deterritorializzazione de las actividades económicas que, al menos en parte, escapan al control de los Estados. En concreto, el mercado escaparía al derecho estatal y se regiría principalmente por normas de diferente procedencia, pública y privada, aprobadas por la comunidad de los agentes económicos. El contrato es el instrumento dinámico que se encuentra en la base de la nueva lex mercatoria aprobada por sujetos de diferentes culturas y procedencia; esta ley, creada por agentes, formalmente incluidos en los diversos ordenamientos jurídicos, puede actuar fácilmente fuera de los límites territoriales, superando la discontinuidad territorial y las barreras de las diferentes soberanías ${ }^{29}$. Por tanto, se ha superado el monopolio de creación del Derecho por fuentes estatales, y en particular por la ley, que sigue siendo formalmente fuente primaria de producción normativa; que, en realidad, estarían duplicadas por la normativa voluntaria procedente de los agentes transnacionales protagonistas de los mercados internacionales. Sobre esto, resulta especialmente difícil negar que se ha construido un gran cliché sobre la globalización que se equipara a la desaparición o, en términos más generosos, decadencia del Estado.

28 B BADIE, La fine dei territori. Saggio sul disordine internazionale e sulla utilità sociale del rispetto (trad. it.), Trieste, 1996, p. 33 y ss.; N. IRTI, Norma e luoghi. Problemi del geo-diritto, Roma-Bari, 2001, p. 65 y ss.; P. Grossi, Globalizzazione, diritti, scienza giuridica, Foro Italiano, 2002, V, p. 152 y ss.; A. Baldassarre, Globalizzazione contro democrazia, Roma-Bari, 2002; F. Galgano, La globalizzazione nello specchio del diritto, Bologna, 2005, p. 30 y ss.; G. Della Cananea, Al di là dei confini statuali. Principi generali del diritto pubblico globale, Bologna, 2009; M.R. Ferrarese, «Globalizzazione giuridica», en Enciclopedia del diritto, Annali, IV, Milano, 2011, passim e 561.

29 F. Galgano, op. cit., p. 56 y ss. 
En efecto, es posible observar la aceptación por parte del Estado de una pérdida en cuanto a la autosuficiencia de su ordenamiento. En muchos casos, el Estado se convierte en el protagonista de procesos de internacionalización al proceder a liberalizaciones, desregulaciones o privatizaciones que facilitan su propio debilitamiento, terminando por legitimar las normas producidas por el activismo de sujetos formalmente no habilitados a tal efecto.

Mientras que el mercado es una realidad artificial que hace inadecuada la dimensión del Estado territorial por el ingenio y la capacidad humana, existe la necesidad de proteger bienes irrenunciables del hombre y de la comunidad en que vive que son, por naturaleza, diremos ex se, ajenos a la dimensión espacial del Estado territorial. Hay intereses vitales que pueden protegerse solo a nivel más amplio, global: en primer lugar, por ejemplo, la protección del medio ambiente y ecosistema. Por otra parte, sobre todo en la actual coyuntura internacional, la protección de la seguridad frente a la amenaza terrorista se consigue a un nivel más alto que el permitido por el ámbito estatal. Estos dos grupos de ejemplos permiten comprender cómo los límites del territorio son superados en la actualidad, y como el poder regulador de los intereses relacionados con el medio ambiente y la seguridad deben identificarse más allá del Estado. En términos más simples, podría sostenerse que en algunos supuestos el Estado se consideraría superado, en el sentido de que no estaría en condiciones de intervenir (por razones económicas, de capacidad organizativa, por decisiones políticas...), mientras que en otros casos ningún Estado sería capaz de proceder de forma resolutiva, ya que objetivamente solo un mayor nivel de intervención sería adecuado (la protección del medio ambiente tampoco podría garantizarla un Estado fuerte solo).

La doctrina se mueve entre la tesis extrema de la desaparición del Estado, como consecuencia de la globalización, y la tesis de la no influencia de la misma en la permanencia de la forma Estado. Otros, adoptando una posición intermedia, sostienen la progresiva transformación del Estado por la globalización. En concreto, la globalización afectaría a la soberanía, lo que implica la disponibilidad del Estado a admitir restricciones con el fin de poder influir recíprocamente en el comportamiento de los demás. En este sentido, no se hace hincapié en la superación del Estado, sino más bien en el aumento de los procesos de independencia entre Estados.

En relación con la globalización, y a los efectos que aquí interesa, con frecuencia se señala cómo los Estados no son los únicos protagonistas de la escena internacional y que, por tanto, existen otros sujetos que pueden actuar en el ámbito estatal sin los límites impuestos por las tradicionales fronteras políticas. En consecuencia, el Estado perdería su papel a favor de entidades políticas infraestatales, sujetos privados, organismos internaciones y supranacionales.

En la práctica, se ha producido un doble ataque a la figura del Estado territorial. De un parte, la intensificación del papel de las autonomías políticas dentro del Estado y la presión de comunidades en busca de su identidad, o incluso de la 
secesión, contribuye a reducir el peso de la tradicional soberanía «interna». De otra, la asunción de tareas cada vez más relevantes por sujetos privados protagonistas de la gestión de los mercados internacionales, y la atribución de funciones a organismos internacionales y supranacionales, ponen de manifiesto la tendencia a eliminar uno de los elementos de la soberanía «externa» debido al pleno dominio del Estado en su territorio, que actualmente se expone a la vigencia de normas creadas por centros de decisión ajenos al Estado como consecuencia de la globalización ${ }^{30}$.

Centrándonos en este segundo aspecto, por un lado, aparecen en la escena nacional e internacional nuevos sujetos diferentes a los Estados, que no necesariamente sustituyen al Estado, pero seguramente se sumen a los Estados; por otro lado, son claramente identificables límites a la soberanía estatal. Todo esto indica que, mientras tradicionalmente se pensaba que la esfera de la política coincidía con la del Estado nación, actualmente, y siendo más realista, se constata que no siempre es válida la ecuación política-Estado.

Estos sujetos son identificables en cualquier persona, en la gran empresa o en organismos internacionales. Se trata de entidades que existen de modo legítimo conforme al derecho nacional o internacional. Además, hay que añadir los que actúan al margen o en contra de la ley, como las organizaciones vinculadas a la delincuencia y el terrorismo.

En el primer caso, sería el individuo el que, gracias a las posibilidades que ofrece la innovación tecnológica, estaría en condiciones de liberarse de las restricciones del Estado pudiendo actuar fuera de su territorio sin tener que preocuparse de sus normas. En concreto, la posibilidad de acceder a redes transnacionales de información y comunicación, «saltándose» al Estado y sus fronteras, no sólo haría innecesario el monopolio estatal de la información, sino también el monopolio de la fuerza convirtiendo a la persona en protagonista y soberano. En el segundo supuesto, sería la gran empresa la que adquiriría un papel protagonista en relación con la creación de mercados transnacionales o de redes de comunicación para llevar a su terreno. Efectivamente, las grandes empresas tienen capacidad para imponer sus reglas en el territorio y a los sujetos e intereses situados dentro del Estado nación. Por tanto, son capaces de influir en la «soberanía económica» de los Estados. En el último caso, son los numerosos organismos $y$ organizaciones internacionales, incluidas las no gubernamentales, las que se muestran adecuadas para afrontar las necesidades comunes a los Estados, las que establecen contactos directos con los implicados dentro del territorio estatal y, al mismo tiempo, se encuentran en situación de actuar sin obstáculos dentro de los límites territoriales.

30 P. Manzini, F. Casolari, A. LOllini, Casi difficili: libertà fondamentali e globalizzazione nella giurisprudenza europea, Torino, 2010; AA.VV., Costituzione economia globalizzazione: liber amicorum in onore di Carlo Amirante, Roma, 2013. Para una contribución sobre esta temática, véase U. DraetTa y M. Fumagalli MERAVIGLIA, ll diritto delle organizzazioni internazionali: parte speciale, Milano, 2011. 


\section{EL MERCADO, LOS DERECHOS, LA DEMOCRACIA}

La presencia de sujetos diferentes de los Estados capaces de actuar más allá de los límites territoriales estatales ha desplazado el centro de atención del territorio al mercado. El desarrollo de la economía mundial habría empujado a un segundo plano las necesidades de poder territorial anteponiendo a ésta las diferentes necesidades de la conquista de los mercados internacionales. Los espacios económicos son objeto de su interés y actuación. El nuevo nomos de control del mercado superaría al tradicional del control del territorio. Por tanto, la soberanía se manifestaría en el pleno control del mercado y los ataques de los intereses privados y públicos se dirigirían al mercado en competencia o alternativo al control estatal.

Esta interpretación de la situación actual de las políticas estatales no es convincente del todo, ya que no resulta fundado que el interés en el mercado haga desaparecer el interés en el control del territorio y, en ocasiones, de la adquisición del territorio, como demuestran las anexiones territoriales a favor de los Estados vencedores de la Segunda Guerra Mundial y los numerosos ejemplos recientes sobre disputas territoriales. Piénsese en el intento de anexión de Kuwait por parte de Irak que originó la Guerra del Golfo o en la separación del territorio del control de la anterior soberanía suprimida, como en el caso de Kosovo. Por tanto, el mercado mantiene una conexión con el territorio y el poder de control del mercado está, directa o indirectamente, relacionado con el territorio.

No obstante, no hay duda que uno de los aspectos de la globalización lo constituye el funcionamiento de entes transnacionales que tienden a moverse en los mercados escapando al control del Estado, o en todo caso, eludiendo dicho control y, a menudo, muestran la debilidad e incapacidad del Estado para hacer cumplir su sistema jurídico de normas relativo al sistema económico. De este modo, se confirmaría el cuestionamiento del principio de soberanía territorial como regulador de las relaciones entre Estados en la comunidad internacional. Sobre esta cuestión, sin embargo, debe señalarse que la superación de las fronteras estatales se conecta también al modo actual de concebir el sistema de garantías.

Desde esta perspectiva, se sugiere que la globalización puede considerarse positiva cuando lleva a difundir la garantía de los derechos y la democratización. De este modo, se fortalecería el ámbito del constitucionalismo con una clara consolidación de los principios confirmados en los últimos siglos tras el impulso de los constituyentes franceses y norteamericanos.

A este respecto, se ha planteado la necesidad de tener presente el éxito de la difusión de las garantías de los derechos civiles y políticos. En general, se ha subrayado que el éxito de los instrumentos internacionales de derechos ha contribuido a ampliar a nivel mundial el rule of law. La Convención Americana sobre Derechos Humanos y la Carta de los Derechos Humanos de la Unión Europea a través del trabajo de los correspondientes Tribunales, pero también la Unión Europea mediante Tribunal de Justicia, han dado un fuerte impulso a las garan- 
tías de los derechos individuales y derechos sociales en una dimensión transnacional. Todos reconocemos este éxito.

Lo que resulta relevante es el hecho de que el conjunto de normas jurídicas sobre garantías ha influido progresivamente en los criterios de funcionamiento de diversos organismos públicos y privados especializados de ámbito internacional. Los principios del debido proceso, contradicción, motivación y revisión de las resoluciones judiciales se han implementado y, por tanto, se deduce una ampliación de las garantías. En este sentido, resultan esclarecedores los estudios de los administrativistas sobre la global polity ${ }^{31}$ y se manifiesta la atención de los constitucionalistas, en el sentido de incluir en sus investigaciones las ampliaciones de los principios del constitucionalismo en los ámbitos de los organismos públicos y privados.

Cabe señalar que al menos en los ordenamientos jurídicos más avanzados se ha producido un desarrollo de la conciencia de los valores establecidos para proteger la dignidad humana, con la consolidación de una fuerza conformatrice que tienen los principios consagrados en algunos importantes instrumentos internacionales en materia de standards mínimo de tratamiento y organización del poder para garantizar los derechos. El respeto a los derechos humanos ha asumido tal relevancia en los últimos tiempos que lleva a considerar los derechos el núcleo de un nomos que es capaz de imponerse sin condiciones a los Estados, verdadera nueva esencia de una soberanía astatale existente en la comunidad internacional. Asimismo, se llega también a posiciones doctrinales que tienden a considerar la tradicional soberanía estatal como incompatible con la garantía de los derechos humanos, llegando a sostener que el concepto mismo de soberanía debería considerarse incompatible con la esencia del Estado constitucional y, por tanto, superado por la primacía de los derechos.

Sin embargo, parece seguro que el rule of law ha tenido una influencia positiva en la ampliación de las garantías de las personas físicas y las empresas. Desde esta óptica, puede afirmarse que el Constitucionalismo ha ampliado su alcance más allá de los ordenamientos estatales.

Este desarrollo, que debe considerarse positivo, sin embargo, no llega a resolver el problema de la falta de legitimación de poder de los organismos ajenos a los Estados que están presentes en los ámbitos de la economía, las finanzas, el comercio, el medio ambiente, la salud, el trabajo... que, operando a nivel transnacional, afectan a los intereses de los ciudadanos y las empresas. Como es sabido, uno de los temas pendientes en la actual fase de integración europea aparece vinculado al insuficiente nivel de legitimidad de las instituciones no estatales que tienen poder para intervenir con autoridad en los intereses de los ciudadanos y las empresas dentro de los diferentes ordenamientos estatales. Para otras organizaciones internacionales el problema de la falta de legitimidad es aún más evidente. Así,

31 Cfr S. Cassese, The Global Polity. Global Dimension of Democracy and the Rule of Law, Sevilla, 2012. 
cuando se va a la infinidad de organismos públicos y privados existentes en el escenario mundial, que se mueven de forma totalmente dispersa y descoordinada, la cuestión está clara: existe una falta total de legitimidad democrática de los organismos que realmente actúan en los informes que se les encomienda.

De este modo, resulta evidente que los agentes de la global policy carecen generalmente de legitimidad democrática. Y no hay ninguna posible referencia a los principios de representación política que afecte a su legitimidad ${ }^{32}$.

Para las entidades públicas y privadas que conforman el variado mundo de los organismos internacionales habilitados para actuar a nivel mundial la situación es complicada y el análisis doctrinal está en vía de sistematización. No solo los creadores son entes privados y públicos, como en el caso de la OMC y la OIT, sino que a menudo existe incertidumbre acerca de las normas y su aplicación. Lo que resulta evidente es que a veces asusta que todo este volumen de organismos de diversa procedencia que se mueven en el escenario internacional tienen la capacidad para producir grandes consecuencias, positivas o negativas, sobre los intereses individuales o colectivos independientemente de cualquier apariencia de legitimación. A propósito de los problemas actuales, un caso extremo lo constituyen los efectos producidos por las valoraciones sobre la calificación de las economías estatales, y su difusión en tiempo real, elaboradas por las célebres agencias de rating ${ }^{33}$. Aquí, no solo no tiene mucho sentido hablar de respeto a los principios democráticos, sino que también transparencia y debido proceso parecen alejados de las evaluaciones positivas de parte de la doctrina sobre estos nuevos participantes en el mundo de las agencias. Con esta notable excepción hay que conformarse al constatar la gradual extensión de las garantías procesales (debido proceso) consideradas la expresión actual del tradicional rule of law.

\section{SOBERANÍA EUROPEA: UN PROBLEMA INEXISTENTE}

Es necesario aclarar un error recurrente en el debate sobre el poder europeo. La frecuente remisión a la indiscutible existencia de un poder fuerte de la Unión Europea ha llevado a hablar, incluso, de una constitución europea; para el Tribunal europeo ya existía ${ }^{34}$, para los Estados aún no, ya que se consideró necesaria la

32 Cfr. G. Palombella, «È possibile una legalità globale? Il Rule of law e la governance del mondo», Bologna, 2012; M. M. WINKLER, Imprese multinazionali e ordinamento internazionale nell'era della globalizzazione, Milano, 2008; F. Pizzolato (dir.), La libertà e potere nei rapporti economici: profili giuspubblicistici, Milano, 2010; V. Kronenberger, M. T. D’Alessio, V. Placco (dir.), De Rome à Lisbonne: les juridictions de l'Union européenne à la croisée des chemins: Mélanges en l’honneur de Paolo Mengozzi, Bruxelles, 2013.

33 C. PINELli, «L'incontrollato potere delle agenzie di rating», en A. BENEDETTI, Le agenzie di rating tra crisi dei modelli di mercato e criticità dei processi di regolazione, en Costituzionalismi.it, 30 de octubre de 2012.

34 Sobre la inexistencia de una Constitución europea utilizando las categorías propias del derecho constitucional elaboradas en relación con los ordenamientos estatales, puede consultarse D. GRIMM, «Una 
aprobación de una Constitución mediante un tratado, que posteriormente fracasaría. Pero hablar de una Constitución sin soberanía carece de sentido. De hecho, el fracaso del proyecto de Constitución ha madurado, ya que como se observó en la cuestión del hecho objetivo de la falta de soberanía.

En estos términos, todo parece sencillo. Pero no es así, ya que tanto la vacilante iniciativa para dotar a Europa de una Constitución, como las confusas opiniones doctrinales presentan complicaciones. $Y$ hay que señalar que en el desarrollo del constitucionalismo, soberanía y Constitución van unidas desde hace tiempo. Como se ha reconocido de forma unánime en la doctrina constitucionalista, la Constitución es un acto derivado del poder constituyente, esto es, un poder originario $y$, por tanto, soberano, completamente innovador que da forma a la unidad política en una perspectiva de estabilidad del ordenamiento. El ordenamiento soberano decide libremente, sin someterse a límites jurídicos, darse una Constitución. Allí donde existe un sistema jurídico basado en principios democráticos, la decisión constituyente aparece íntimamente ligada a la voluntad popular y, en consecuencia, goza de una fuerte legitimación. Así, en la teoría clásica de la Constitución, ésta aparece vinculada no sólo al Estado, sino también al rasgo que lo identifica, la soberanía, concebida actualmente, no como poder último sin límites y garantías, sino como capacidad de autosuficiencia política y, por ello, de independencia de otros centros de poder. De este modo, se trata de un poder legitimado democráticamente.

Sin embargo, los principios constitutivos de la Unión incorporados en los Tratados derivan de las decisiones de los Estados miembros. No sería suficiente el recurso al término Constitución para poder sostener que la «Constitución» europea entra en la categoría de constituciones, tradicionalmente consideradas como decisiones fundantes de las comunidades políticas que se definen como Estados. A estas conclusiones debe llegarse, ya que no es suficiente identificar la existencia de principios y valores y la regulación de los derechos y la organización, que se asemejan a la sistemática de una Constitución estatal. La construcción de una comunidad, y de la Unión, se basa por definición en el principio de la no afirmación de una forma de integración que lleve a anular comunidades políticas nacionales o estatales. Mientras el Estado constitucional se basa, como se ha reconocido pacíficamente, en el principio de unidad política, este principio no existe para la Unión Europea. La fórmula prevista es la de integración que garantice el mantenimiento de las identidades y diversidades de los Estados miembros. Y el principio de diversidad es claramente estabilizador, lo que caracteriza el vínculo de unidad entre los integrantes de la Unión. Al mismo tiempo, es necesario cuestionarse cuál es la fuente del ordenamiento jurídi-

costituzione per l'Europa», en G. Zagrebelsky, P.P. Portinaro, J. Luther, Il futuro della costituzione, Torino, 1996, 345. Sobre las diferentes opiniones doctrinales sobre el tema, G. DE VERGOTTINI, voz «Costituzione europea», en Enciclopedia del diritto, Annali 1, Milano, 2007, pp. 449-472. 
co de la Unión y en este punto surge un dato clarificador y decisivo. La fuente última del derecho que la Unión adopta y aplica deriva de la voluntad de los Estados miembros fundadores, que a pesar de estar condicionados por los tratados firmados siguen siendo Estados soberanos y, entre otros, participan activamente en la formación de importantes actos jurídicos y de control, y mantienen inalterado su poder para modificar las bases de toda la construcción «constitucional» de la Unión mediante el poder de revisión de los tratados, como garantía última de los principios de identidad y diversidad, y que recientemente, han querido codificar el derecho de desistimiento de la misma ${ }^{35}$. Realizadas estas afirmaciones, se constata que respecto al espacio se han adoptado las decisiones de los órganos comunitarios que no han podido asumir la función de revisar sus «Constituciones».

Esta alusión sirve para recordar que existe conceptualmente una identificación entre la soberanía (originarietà) y el poder constituyente unido a la necesidad, en el actual Estado «constitucional», de una legitimación democrática. La legitimación de las instituciones europeas debe reconducirse a los Estados, y solo indirectamente a la voluntad popular de cada ordenamiento estatal. La atribución de amplios poderes, sobre todo en relación con el control monetario y la denominada soberanía monetaria, no son de naturaleza tal que permitan superar la legitimación del Estado por parte de una supuesta legitimación europea ${ }^{36}$. Dicho esto, no existiría ningún problema si madurase un ente de tipo federal, de acuerdo con el indirizzo del órgano de justicia de la Unión, que permitiría identificar la existencia de un pueblo europeo que legitimase la Constitución, aun cuando ésta fuera inicialmente «concedida» por los Estados. Pero en la actualidad no existe un pueblo europeo y los Estados en ningún momento han manifestado el propósito de renunciar a su soberanía, sino que únicamente han pretendido atribuir competencias concretas de forma voluntaria a través de los tratados. La consecuencia inevitable es negar la posibilidad de identificar un poder supremo europeo alternativo a la soberanía de los Estados y una Constitución europea diseñada de acuerdo con el modelo estatal.

35 Sobre la incidencia de los tratados europeos en el principio de soberanía:. CANNizZARO, «Esercizio di competenze e sovranità nell'esperienza giuridica dell'integrazione europea», en Rivista di diritto. costituzionale, 1996, p. 75 y ss.; L.M. DiEz-PiCAZo, «What does it mean to be a state within the European Union?», en Riv. it. dir. pubbl. comun., 2002, p. 651 y ss.; R. ToniatTI, «Forma di stato comunitaria, sovranità e principio di sovranazionalità: una difficile sintesi», en Dir. pubbl. comp. eur., 2003, pp. 15521560; G. Morbidelli, «Il passaggio (incompiuto?) Dalla logica internazionale/comunitaria del sistema UE/CE ad una logica interna/costituzionale/federale dell'Unione», en Dir. pubbl. comp. eur., 2003, p. 1700 y ss.; U. Draetta, «La Costituzione europea e il nodo della sovranità nazionale», en Dir. eur., 2004, p. 526 y ss.; E. Cannizzaro, La Costituzione pluralista. A proposito della natura giuridica del Trattato costituzionale, in Dir. eur., 2005, p. 1 y ss.; PAtrono M., "Sovranità statale e costituzione europea», en S. Gambino (dir.), Trattato che adotta una costituzione per l'Europa, costituzioni nazionali, diritti fondamentali, Milano, 2006, p. 145 y ss.

36 Sobre la competencia entre las dos legitimidades y la permanencia de la legitimidad del Estado en detrimento de la europea, véase B. DE GIOvanni, op. cit., p. 29 y ss. 


\section{RENUNCIAS A LA SOBERANÍA Y SOBERANÍA COMPARTIDA: UN PROBLEMA INÚTIL Y FALSO}

En consonancia con lo anterior, debe aclararse la confusión de la supuesta asignación de soberanía a la Unión Europea en virtud de la abdicación del Estados para ejercer sus poderes. Si los Estados se limitan a transferir a la Unión competencias «soberanas» (como rasgo de su soberanía), el mero hecho de la transferencia no convierte a la Unión en soberana. Y esto se aplica incluso cuando un órgano de la Unión, el Tribunal de Justicia, favorece una solución de autosuficiencia del ordenamiento comunitario extralimitándose en una situación reconducible al ámbito de la soberanía. Pero, como se señaló anteriormente, la Unión carece de capacidad para imponerse y ser aceptada como superior a los Estados, ya que carece de una elección decisiva y de legitimidad popular, elemento que actualmente caracteriza a la soberanía en los ordenamientos jurídicos basados en principios democráticos. En efecto, no basta con disponer de poder real, sino que éste debe estar legitimado mediante la voluntad popular. Por tanto, no existe soberanía si ésta tuviera que encontrarse únicamente en la atribución de competencias que caracteriza a la soberanía, a las que los Estados renuncian pudiendo, en teoría, recuperarlas haciendo uso del derecho de retirada de la Unión.

Se ha afirmado que habría una «distribución de poderes soberanos entre órganos estatales e instituciones europeas». Por tanto, sería necesario renunciar a un concepto unitario de soberanía y aceptar una repartición ${ }^{37}$. Partiendo de la idea de «disolución» de la soberanía estatal, esta tesis sostiene que debe admitirse la existencia de una competencia entre Estados y la Unión, «cada uno dotado de su propia autonomía y discrecionalidad en el plano internacional y a fin de afirmar su autonomía y originarietà» ${ }^{38}$. Esta interpretación del fenómeno europeo no parece admisible. Es cierto que existe una distribución de poderes, pero los poderes soberanos no pueden ser los de la Unión, ya que solo un ente soberano tiene poderes soberanos. La mera transferencia de atribuciones de un ente soberano a otro no soberano no convierte en tal a este último. Por otro lado, no se pueden equiparar los Estados y la Unión en la declaración de la respectiva autosuficiencia y originarietà. Los Estados ya la tienen, mientras que solo la Unión podría eventualmente aspirar a la soberanía.

La consideración de que los Estados, habiéndose transferido competencias a un organismo exterior, no podían dejar de dotarlo de las prerrogativas necesarias para su ejercicio es correcta. Pero esto no significa que deba considerase tales competencias como soberanas y admitirse un reparto de soberanía entre

37 Cfr. V.N. Walker, «Late Sovereignty in the European Union», Sovereignty in Transition, Oxford. 2003, 14; V.U. Haltern, Was bedeutet Souveränität?, Tübingen, 2007, p. 22 y ss.

38 E. Cannizzaro, op. cit., p. 118 y ss. 
Estados y Unión. La Jurisprudencia del Conseil Constitutionnel y el Tribunal Constitucional ha sido muy precisa al subrayar el mantenimiento de la soberanía de los Estados miembros. El Conseil reconoce límites a la soberanía francesa y se preocupa por reclamar una ley de revisión constitucional en virtud del art. 54 de la Constitución con el fin de examinar la conformidad a la Constitución de la atribución de competencias a la Unión mediante el tratado «que afecta a las condiciones esenciales de ejercicio de la soberanía nacional» (Decisión n. ${ }^{\circ}$ 2004-505 DC). El Tribunal Constitucional español, requerido para examinar la conformidad del tratado a la Constitución ex art. 95.2 de la misma, recuerda de forma reiterada el mantenimiento de la soberanía estatal. La atribución de competencias a la Unión no puede considerarse una renuncia a su titularidad, sino una «cesión del ejercicio de dicha competencia» y los límites derivados del tratado «a las facultades soberanas del Estado» se consideran «admisibles solo si el derecho europeo es compatible con los principios fundamentales del Estado democrático de Derecho previsto por la Constitución nacional» (Declaración 1/2004). A su vez, la European Union Committee de la House of Lords en el examen del proyecto de tratado constitucional elaborado por la Convención Europea señaló que las competencias europeas fueron asignadas dentro de las atribuciones conferidas por los Estados y que la Unión «sigue siendo una unión de Estados soberanos» ${ }^{39}$. Por último, la sentencia del Bundesverfassungsgericht sobre el Tratado de Lisboa, de junio de $2009^{40}$, ha puesto de nuevo límites a la ampliación de la doctrina que limita el papel predominante de los Estados miembros en el momento actual de las relaciones entre el orden estatal y el europeo. La competencia de la competencia se mantiene firmemente en manos del Estado, único garante de un verdadera democracia política parlamentaria.

En general, «los tribunales de los Estados miembros sostienen que la autoridad del derecho de la UE sobre los Estados tiene su origen en la Constitución nacional, y en la misma buscan la base soberana de la primacía y eficacia directa del derecho europeo» ${ }^{41}$.

En realidad, la noción de la divided sovereignty ${ }^{42}$ ha sido utilizada en algunas experiencias federales (por ejemplo, Estados Unidos). Sin embargo, en aquellos supuestos no se discutió la existencia de una Constitución federal, al margen de las precedentes de los Estados miembros, y la Constitución federal se presentó como superior. En el caso de la Unión europea existe la soberanía de los Estados,

39 Cfr. 41st Report: The Future of Europe-The Convention's Draft Constitutional Treaty, chapter 2, par. 55.

40 BVerfGE 123267 (2009) cit.

41 Así, H. Lehmann, Democrazia europea, identità costituzionale e sovranità. La sentenza sul Trattato di Lisbona della corte costituzionale tedesca: alcune ripercussioni, Documento de la Comisión de Asuntos constitucionales del Parlamento europeo, septiembre 2011.

42 Sobre la soberanía compartida, véase R.O KEHOANE, «Ironies of Sovereignty: the European Union and the United States», en Journal of Cpmmon Market Studies, 2002, p. 744 y ss. Contra véase, O. BEAUD, Théorie de la Fédération, Paris, 2007; D. Grimm, Souveraineté, cit., p. 600 y ss.; M. Raveraira, La sovranità degli stati, cit, p. 39 y ss. 
aunque limitada por sus libres decisiones, mientras que la Unión carece de soberanía que, por otro lado, jamás ha sido reivindicada por la Unión.

\section{A MODO DE CONCLUSIÓN}

En conclusión, se confirma el mantenimiento del actual modelo «Estado» acompañado de su soberanía. Y ello, pese a las reiteradas críticas. A las señaladas con anterioridad, habría que añadir en los últimos tiempos la grave crisis económica y financiera que se refleja tanto en el Estado, como en otras entidades políticas diferentes del Estado tanto internas como externas. Ante esta situación de emergencia económica el Estado se muestra incapaz de afrontarla de forma convincente. Así, resulta inevitable recurrir a la cooperación entre Estados y a organismos supranacionales que, por sí mismos, resultan también insuficientes. En este complejo contexto, la soberanía estatal no ha desaparecido del todo, aunque se ha visto fuertemente limitada y restringida tanto por los vínculos formales recogidos en los tratados suscritos libremente por los Estados, como por las circunstancias y acciones de organismos internos y externos no siempre caracterizados por el respeto al Derecho. Por tanto, es cierto que la soberanía no es una característica del poder definitivamente fija y determinada. Se manifiesta cualitativamente diferente de unos Estados a otros. De este modo, se muestra recesiva o mejorable en función de las circunstancias y de las diferentes condiciones temporales y fácticas. Podríamos afirmar que se caracteriza por una inevitable variabilidad (variabilità) ${ }^{43}$. Basta con examinar el diferente papel de los Estados en el seno de la Unión Europea. Formalmente todos son iguales, pero sabemos, sin duda alguna, que la soberanía alemana cuenta más que la de los restantes Estados. Por tanto, podríamos afirmar que hay soberanías fuertes y soberanías débiles o frágiles. Además, y sobre todo, la soberanía constituye, como se ha señalado, un fenómeno «dinámico» en la medida en que evoluciona con el tiempo, adaptándose a los diversos contextos de referencia, ampliándose o reduciéndose de manera que los sujetos titulares no tengan grandes desacuerdos y funcionen basándose en la cooperación leal ${ }^{44}$, como debería suceder en el marco de la actual Unión Europea.

$$
* * *
$$

TITLE: The persistent Sovereignty

ABSTRACT: It is analized the concept of sovereignty to see if its useful inside the inevitable integration intergovernmental organizations.

43 En este sentido, véase M. Raveraira, op. cit., p. 43.

44 Sobre el principio de cooperación como instrumento útil para resolver las discrepancias entre el nivel estatal y el nivel comunitario, cfr. D. GRIMM, Souveraineté, cit., p. 601 y ss. 
RESUMEN: Se analiza en el trabajo el concepto de la soberanía para valorar si continúa siendo un concepto útil para definir la naturaleza del Estado, en la medida en que resulta evidente su inevitable integración en organizaciones intergubernamentales consideradas necesarias en el panorama internacional.

KEY WORDS: Sovereignty, State, Intergovernmental organizations.

Palabras Clave: Soberanía, Estado, Organizaciones intergubernamentales.

FECHA DE RECEPCIÓN: 05.09.2014 FECHA DE ACEPTACIÓN: 29.07.2015 
